\title{
An attempt to obtain replicate learning curves in the split-brain cat
}

\author{
HAROLD GULLIKSEN \\ Princeton University and Educational Testing Service, Princeton University, Princeton, New Jersey 08540
}

and

THEODORE VONEIDA

Case Western Reserve University, School of Medicine, Cleveland, Ohio 44106

\begin{abstract}
Sperry (1961) and others working on split-brain learning reported that the two halves function in a nearly identical manner, giving excellent controlled replication of a learning problem. Such a situation furnishes an excellent opportunity for investigating learning curve parameters to differentiate random error from a systematic discrepancy between data and learning theory. The present experiments were carried out with cats trained in a tactile discrimination apparatus, sometimes using the left paw, and sometimes the right paw. Two groups of animals were used, one trained at Princeton University, and the other at Case Western Reserve University. The data were analyzed in terms of the Audley-Jonckheere (1956) learning model and also in terms of total trials, total correct responses, and total errors to criterion. The data gave no clear evidence that second brain learning replicated first brain learning. Only one problem showed high correlations between right and left brain learning.
\end{abstract}

This study of learning curves in normal and split-brain cats investigated primarily the extent to which the course of learning using one hemisphere of a slit-brain animal may be regarded as repeating or replicating the course of learning using one hemisphere of a split-brain animal may be regarded as repeating or replicating the learning performance and determining individual characteristics of learners.

In interpreting the results of any such study, it is important to determine the extent to which the lack of agreement between theory and data is due to random errors in the data, or to systematic deviations, indicating some inadequacy of the learning theory. It must be emphasized that the usual goodness of fit test does not enable the investigator to distinguish random errors from systematic deviations from theory. It simply gives a measure of the total deviation of data from theory. One customary procedure for assessing the magnitude of random errors is to repeat or replicate the experiment and to regard the difference between the two or more replications as an indication of the extent of random error.

One of the severe handicaps of studies of learning has been the impossibility of repetition or replication of a learning study to see if similar learning ability parameters are found on repeating the experiment. If a subject has learned a task, and a learning curve has been

*This research was supported in part under Contract N00014-67-A-0151-0006, and National Science Foundation Grant GB 8023X with Princeton University, Project on Mathematical Techniques in Psychology, Harold Gulliksen, Principal Investigator; by the National Institute of Child Health and Human Development, Research Grant 5 P01 HD01762, to Educational Testing Service, Norman Frederiksen, Principal Investigator; and by Unted States Public Health Service, Grant No. MH-07051, to Case Western Reserve University, Theodore Voneida, Principal Investigator. recorded, then it has been impossible to repeat the experiment, to obtain a second determination of the parameters. If the same learning task is used again with the same subject, then he already knows the solution; if a different but hopefully reasonably similar task is used with the same subject, then due to positive or negative transfer, a learning curve different from the first one is expected; if a different subject is used, then the new subject's learning ability for this task may well differ from that of the first subject. In all three cases, one has no replication of a given learning curve, with a reasonable expectation of replication (except for random error) of the parameters characterizing the learning process. This means that it has never been possible in the 100 years of psychological study of learning to differentiate random error in the fit of learning theory to data from systematic deviations between theory and data due to inadequacy of the learning theory.

Research by Sperry and others, summarized by Sperry (1961) used the technique of sectioning the corpus callosum, and studying separately the functioning of the right and left halves of the brain. Sperry (1961) states, "One obvious advantage of the split-brain preparation lies in the factor of built-in controls for all sorts of experiments ranging from short term studies on innate organization to studies on the long term effects of early experience on adult behavior. These controls are not only of the homozygous identical twin type, but are equated also for almost all experientially derived organization implanted up to the time of splitting." These contralateral cerebral controls are thus of a quality almost impossible to obtain by using different animals. 
In a study of tactile discrimination in normal and split-brain cats, Stamm and Sperry (1957) state "The relearning curves (for corpus callosum sectioned cats) then followed the course of the curves for the first paw. The marked agreement between the two curves of each task was evident in the majority of discriminations of the other three cats." Paired learning curves are shown for one of the four animals studied with the statement that the learning curve for one hemisphere is markedly similar to the relearning curve for the other hemisphere.

The evidence for agreement between the original and relearning curves in split-brain animals has depended on visual inspection of the curves, or on overall summary measures such as total trials, or total errors to criterion. Such measures would not distinguish, for example, between curves which showed very few errors to criterion, because the subject started with a low probability of a correct response and learned very rapidly, from the case where the subject made few errors primarily because he started with a very high probability of a correct response and learned slowly.

In view of the statements asserting practical identity of functioning for the two hemispheres and of the great value for the study of learning that would be achieved if learning curves could be replicated, the present study of hemispheric functioning was undertaken, using as measures of similarity of functioning parameters of a learning curve based on Thorndike's law of effect as formulated by Gulliksen $(1934,1953)$, and generalized by Audley and Jonckheere (1956). As an additional check, we also used the more usual measures of total trials and total errors to criterion, since these two methods of analysis can give different results.

\section{PROCEDURES}

In the present experiment, the methods and apparatus used by Stamm and Sperry (1957) and Sperry (1961) were followed with some modifications. Two groups of animals were trained under the above conditions. The two groups of cats were used in the investigation to test the learning of tactile stimuli, one group at Princeton University in the Psychology Department animal laboratory (Group PR) and one group under the supervision of Theodore Voneida at the Department of Anatomy, Case Western Reserve University (Group WR). There were additional features for the PR group. The pedals were wired to a keypunch so that right or wrong responses were recorded, along with identifying codes, on IBM cards. Also, two additional problems, which proved to be very difficult, were given to the PR group, and the animals in these cases refused to work. A change was then made in the food reward. Instead of dry cat food pellets, small pieces of cooked liver were dropped from the automatic feeder when the "correct" pedal was pressed. This change in food brought a marked change in motivation, such that the cats consistently pressed the pedals, whether or not they learned the problem.

Three pairs of tactile stimuli, as shown in Table 1, were presented to nine cats in the WR group. This group consisted of two normal subjects (Sy and Am), four with section of the corpus callosum and anterior commissure $(\mathrm{Pa}, \mathrm{Ba}, \mathrm{Ar}, \mathrm{Ho})$, and three with section of corpus callosum only ( $\mathrm{Ch}, \mathrm{To}, \mathrm{Ca})$. Midline surgery was performed by Voneida, either before or after the first pair of problems. Both left and right paws were trained on each pair of stimuli.

The PR group of five cats consisted of 6-month-old naive animals. They began the series of experiments in the normal condition and were trained on three pairs of stimuli, first with one paw, then with the other paw. For each pair of stimuli, two cats had a given stimulus positive, while the other three cats had the other stimulus positive. Four animals then had the corpus callosum and anterior commissure sectioned after the fifth or sixth problem. A fifth cat was normal throughout the experiment. After the first six problems, the PR cats were trained on three new pairs of stimuli, each with left and right paw, the positive stimuli differing for two of the four operated animals. The stimuli and problems used for the PR cats are shown in Table 2. The stimulus which was positive for Problems 11 and 12 was reversed for Problems 13 and 14.

Surgery was performed under general nembutal anesthesia and direct control, as described previously (Voneida, 1963). Subsequent to all training procedures, the brains were perfused in Voneida's laboratory and, after a suitable period of fixation, were frozen and serially sectioned. All sections were stained according to the Weil method, and microscopic examination revealed the completeness of midline section in each case, including both the three with corpus callosum only, and the eight with corpus callosum and anterior commissure.

\section{Training Procedure}

It was usual for the animals to show a strong position habit at first, which was usually followed by a lesser position habit on the opposite side. To eliminate this, and to keep that animal working on the problem, it was found that holding the incorrect pedal in place after a series of incorrect responses led the animal to try the alternate or correct pedal. At first, the animal was allowed to make 10 incorrect responses before he was led to correct himself. Later, a run of five incorrect responses was permitted before the incorrect pedal was held, leading to a correct response when corrected. If the animal did not achieve success, either by trying an alternate pedal of his own accord, or by the experimenter inducing the change by holding the pedal, the cat often refused to work.

The WR animals were regularly given 50 trials per day. The criterion of learning was $90 \%$ or more correct responses on 3 consecutive days. If this level was not reached, the experiment was terminated after the animal had reached a plateau, or had fallen consistently below its highest level of performance. The PR group was given 50 trials per day or 30 correct responses, whichever came first. The criterion of learning was $90 \%$ correct responses on 3 consecutive days. For both the WR and PR

Table 1

Sequence of Problems Used for WR Group

\begin{tabular}{ccll}
\hline Code & Order & \multicolumn{1}{c}{ Stimuli } & \multicolumn{1}{c}{ Material and Shape } \\
\hline $\mathrm{ba}$ & 1,2 & Brush vs. flat & Bristle brush vs. flat wood block \\
$\mathrm{dc}$ & 3,4 & Round vs. wedge & Smooth metal half-sphere vs. metal wedge \\
$\mathrm{hg}$ & 5,6 & Horizontal vs. vertical & Metal ridges with spaces between \\
\hline
\end{tabular}

Note-Code letter on left signifies positive stimulus. Surgery done before ba problem or after it, sectioned corpus callosum (cc), and anterior commissure (ac). 
Table 2

Sequence of Problems Used for PR Group

\begin{tabular}{lcll}
\hline Code & Order & \multicolumn{1}{c}{ Stimuli } & \multicolumn{1}{c}{ Material and Shape } \\
\hline ba or ab & 1,3 & Brush (b) vs. flat (a) & $\begin{array}{l}\text { Bristle brush vs. flat wood block } \\
\text { Positive stimulus reversed from Problem 1 to 3 } \\
\end{array}$ \\
dc or cd & 2,6 & Round (d) vs. wedge (c) & Smooth metal half-sphere vs. metal wedge \\
fe or ef & 4,5 & Doormat (f), sponge (e) & Tined rubber doormat vs. firm rubber sponge \\
hg or gh & 7,8 & Horizontal (h), vertical (g) & Flat metal bars with spaces between \\
df or fd & 9,10 & Round (d) vs. doormat (f) & Smooth metal half-sphere vs. tined rubber doormat \\
ba or ab & 11,12 & Brush (b) vs. flat (a) & Bristle brush vs. flat wood block \\
ab or ba & 13,14 & Flat (a) vs. brush (b) & Flat wood block vs. bristle brush \\
& & & Reversal of positive stimulus from Problem 11, 12 \\
\hline
\end{tabular}

Note-Code letter on left signifies positive stimulus. Surgery done as indicated in later tables. The pairs of problems were done with the same positive stimulus for both paws, except Problems 1 and 3.

groups, a random order of stimuli was used. If the animal learned to change and press the alternate pedal whenever an error was made, it was possible to get $66 \%$ correct responses in a day. It was considered that the animal could not learn to discriminate members of a pair of stimuli unless one of the two paws learned the problem to $80 \%$ correct for 3 consecutive days. The pair of stimuli hg was different for the PR and WR groups. For the WR group, hg was a set of horizontal ridges vs vertical ridges made of metal with spaces between. In an attempt to get a slightly more difficult problem than ba (brush-flat), the PR group was given hg as horizontal vs vertical flat bars with spaces between.

\section{Methods of Analysis}

The present investigation has taken a theoretical formulation of learning, the Audley-Jonckheere (1956) learning model of which Gulliksen $(1934,1953)$ is a special case, and determines the values of the parameters of this model from the data on the split-brain cat learning records. James Ramsay (1970) of McGill University has written a computer program for estimating parameters in the Audley-Jonckheere learning model and for carrying out the analysis of the learning data.

In applying the learning model proposed by Audley and Jonckheere (1956) to a learning problem in which there are only two possible responses, correct and incorrect, the probability of a correct response on any trial is the ratio of the habit strength for that response on any trial to the sum of the habit strengths for the two possible responses. The sequence of learning trials commences with some initial probability of a correct response $\mathrm{Rho}_{0}$. The response on any given trial affects the probability of a correct response through the increase or decrease of the habit strength of the correct and/or incorrect response. The following relationships may be defined:

$$
\begin{aligned}
\mathrm{Rho}_{0}= & \text { the initial probability of a correct } \\
& \text { response }\left(\rho_{0}\right)
\end{aligned}
$$

Alpha $=$ an amount by which a correct response increments the correct habit strength $(\alpha)$

Gamma 1-Alpha = an amount by which a correct response increments the incorrect habit strength $\left(\gamma_{1}-\alpha\right)$

Beta $=$ an amount by which an incorrect response increments the correct habit strength $(\beta)$

Gamma 2-Beta = an amount by which an incorrect response increments the incorrect habit strength $\left(\gamma_{2}-\beta\right)$. See Table 3 .

If, for example, during 12 trials a correct response is given on five trials, and an incorrect response on 7 trials, then the strength of the correct response would be increased by $5 \alpha+7 \beta$. The strength of the incorrect response would be incremented by $5\left(\gamma_{1}-\alpha\right)+7\left(\gamma_{2}-\beta\right)$.

Let $X_{i}$ indicate the response on trial number $i$, taking the value of 1 if the response is correct and 0 if it is incorrect. Let

$$
K_{n}=\sum_{i=1}^{n} x_{i}
$$

be the total number of correct responses made in trials 1 to $n$, inclusive. Then the probability of a correct response on trial $(n+1)$ is a function of the initial probability of a correct response $\left(\mathrm{Rho}_{0}\right)$, the total number of previous correct responses $\left(\mathrm{K}_{\mathrm{n}}\right)$, and the values of Alpha, Beta, Gamma 1, and Gamma 2 as defined above. According to the Audley-Jonckheere (1956) model (see Equation 2 on page 89 in reference), the probability of a response on any specified trial is the ratio of the habit strength for the response on that trial to the sum of the habit strengths for the two possible responses. This is given by

$$
\begin{aligned}
\mathbf{P}_{\mathbf{r}}\left[\mathrm{X}_{\mathbf{n}+1}\right. & \left.=1 / \mathrm{K}_{\mathbf{n}}\right] \\
= & {\left[\rho+(\alpha-\beta) \mathrm{K}_{\mathbf{n}}+\mathrm{n} \beta\right] /\left[1+\left(\gamma_{1}-\gamma_{2}\right) \mathrm{K}_{\mathbf{n}}+\mathrm{n} \gamma_{\mathbf{2}}\right] . }
\end{aligned}
$$

This model can be distinguished in important practical ways from certain Markov and linear operator models (which are special cases of habit strength models, Atkinson 1964, for example). This model readily accommodates very slow learning such as one finds in some types of animal studies. The distinguishing feature is the effect of a correct response on learning late in the sequence. The habit strengths become progressively larger and the relative effects of the constant increments become progressively smaller. Finally, learning in this model depends only on the number of correct responses prior to a given trial $\left(\mathrm{K}_{n}\right)$, and not on the probability of a correct response on the previous trial.

\section{RESULTS}

The results of the analysis in terms of the parameters Table 3

\begin{tabular}{lccc}
\hline & \multicolumn{3}{c}{ Increase in Strength of } \\
With Occurrence of & $\begin{array}{c}\text { Correct } \\
\text { Response }\end{array}$ & $\begin{array}{c}\text { Incorrect } \\
\text { Response }\end{array}$ & $\begin{array}{c}\text { Both } \\
\text { Responses }\end{array}$ \\
\hline Correct Response & $\alpha$ & $\gamma_{1}-\alpha$ & $\gamma_{1}$ \\
Incorrect Response & $\beta$ & $\gamma_{2}-\beta$ & $\gamma_{2}$ \\
\hline
\end{tabular}


Table 4

Range of Values for Learning Parameters $\mathrm{Rho}_{0}$ and Alpha

\begin{tabular}{llllll} 
& & \multicolumn{2}{c}{ Normal } & \multicolumn{2}{c}{ Operated } \\
& & Lowest & \multicolumn{1}{c}{ Highest } & \multicolumn{1}{c}{ Lowest } & \multicolumn{1}{c}{ Highest } \\
\hline Rho $_{0}$ & WR & 0.3996 & 0.6215 & 0.3126 & 0.5995 \\
Rho $_{0}$ & PR & 0.2431 & 0.7084 & 0.1612 & 0.5996 \\
Alpha & WR & 0.0 & 0.005129 & 0.000305 & 0.01834 \\
Alpha & PR & 0.0 & 0.06342 & 0.0 & 0.007168 \\
\hline
\end{tabular}

of the Audley-Jonckheere model are summarized in Table 4.

The values for $\mathrm{Rho}_{0}$, the initial probability of a correct response for the normal animals varied from about .25 to .70 . In general, the higher values were for learning with the second paw, and lower values for learning with the first paw, as would be expected if there is initial transfer of training. The values of $\mathrm{Rho}_{0}$ were somewhat lower for the operated animals and the values for learning with the second paw were about half higher and half lower than the values for learning with the first paw.

For both the normal and operated animals, learning depended primarily on values of alpha which ranged from 0.0 to 0.063 . In the few cases where the value of alpha was 0.0 , indicating no learning due to alpha, or the effect of the correct response, there was a small positive value for beta, indicating that learning was due to the effect of an incorrect unrewarded response increasing the probability of the correct response. The other two parameters indicating effect on the probability of the incorrect response, $\left(\gamma_{1}-\alpha\right)$ and $\left(\gamma_{2}-\beta\right)$, were essentially zero in all cases.

The values of alpha and beta were generally lower for the operated than for the normal animals, indicating a faster learning rate for the normals. For the operated

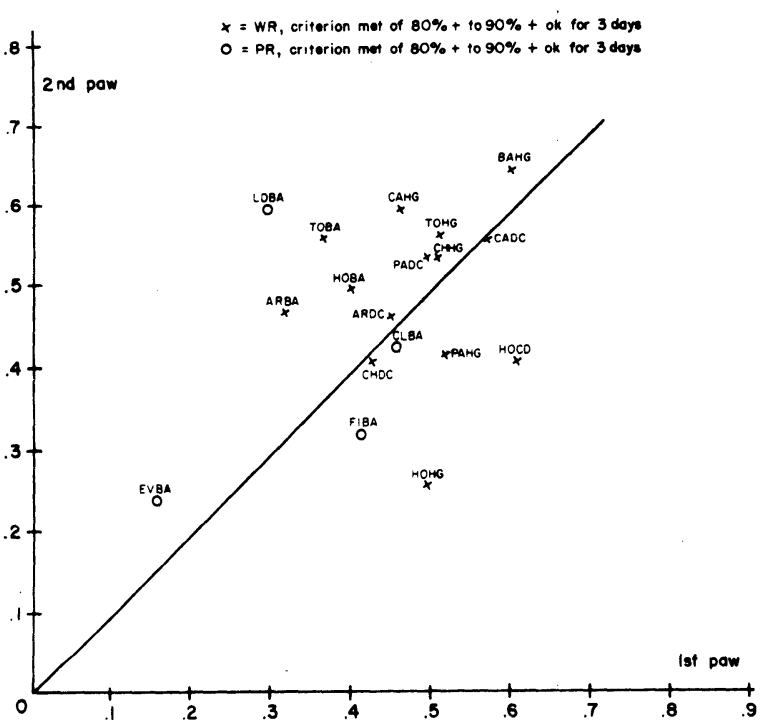

Figure 1. Learning parameter, $\mathbf{R h o}_{0}=$ initial probability of a correct response, split-brain cats.

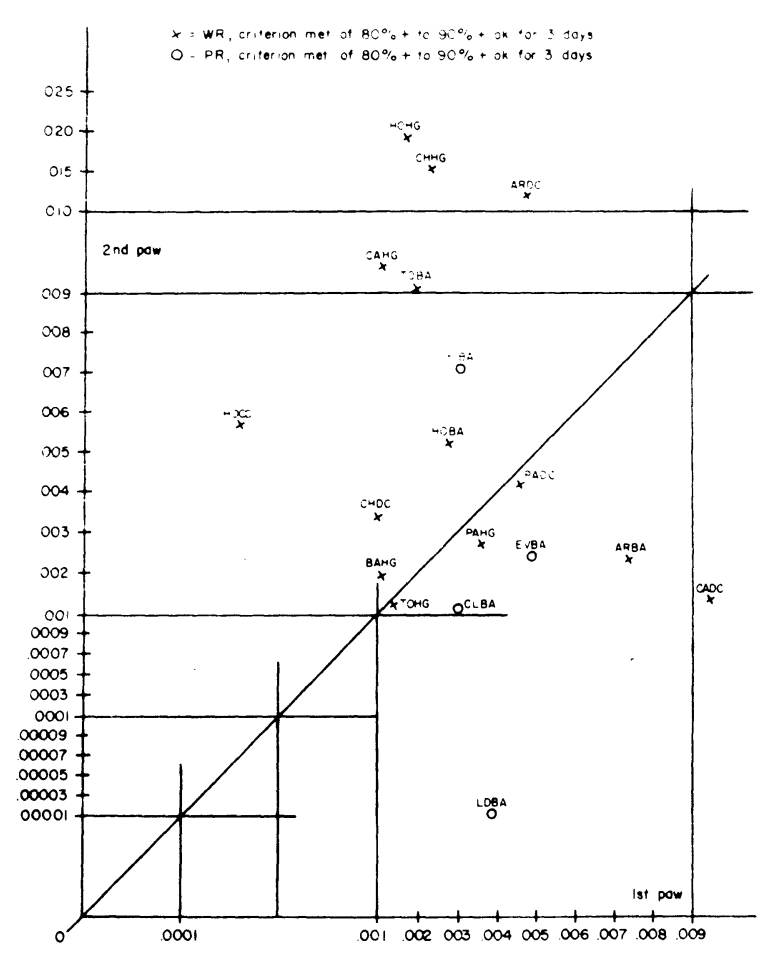

Figure 2. Learning parameter, alpha = effect of correct response on strength of correct response, split-brain cats.

animals, the alpha or beta values were sometimes higher and sometimes lower for the second paw, indicating no consistent transfer effect.

The degree of agreement between the two hemispheres for both the WR and PR groups for $\mathrm{Rho}_{0}$ is shown in Figure 1. From the graph it can be seen that there is not a trend for low values for the first paw to match low values for the second paw, or for high values for the two paws to be paired. Correspondingly, the comparison of first and second paws for the values of alpha for both WR and PR groups is shown in Figure 2. Again from the graph, it can be seen that low values for the first paw are not especially associated with low values for the second paw, and correspondingly there is no marked tendency for high values for the two paws to be associated. In order to give a quantitative measure of the degree of agreement shown in Figures 1 and 2, three indices of agreement between right and left paw results were computed.

$$
r=\Sigma x y /\left(\Sigma x^{2} \Sigma y^{2}\right)^{1 / 2}
$$

(The usual Pearson correlation coefficient)

$$
\mathrm{R}_{1}=2 \Sigma \mathrm{xy} /\left(\Sigma \mathrm{x}^{2}+\Sigma \mathrm{y}^{2}\right)
$$

(Index of deviation score equality) 
Table 5

Relationships Between Left-and Right-Paw Learning Measures in Split Brain Cats: Parameter Values in Learning Tactile Problems

\begin{tabular}{lcccc}
\hline Parameter & $\mathrm{R}_{2}$ & $\mathrm{R}_{1}$ & $\mathrm{r}$ & Number of Cases \\
\hline Rho $_{0}$ & 0.132 & 0.215 & 0.217 & 4 Pairs PR (all ba) \\
$\mathrm{Rho}_{0}$ & 0.081 & 0.083 & 0.083 & 14 Pairs WR \\
Alpha & -0.150 & -0.104 & -0.195 & 4 Pairs PR (all ba) \\
Alpha & 0.045 & 0.045 & 0.076 & 14 Pairs WR \\
Beta & 0.0 & $0.0 / 0.0$ & $0.0 / 0.0$ & 4 Pairs PR (all ba) \\
Beta & $0.0 / 0.0$ & $0.0 / 0.0$ & $0.0 / 0.0$ & 14 Pairs WR \\
\hline
\end{tabular}

$$
\mathrm{R}_{2}=(2 \Sigma \mathrm{xy}-\mathrm{W}) /\left(\Sigma \mathrm{x}^{2}+\Sigma \mathrm{y}^{2}+\mathrm{W}\right)
$$

(Index of gross score equality), where $\mathrm{W}=(1 / 2 \mathrm{~N})(\Sigma \mathrm{X}-\Sigma \mathrm{Y})^{2}, \mathrm{X}$ and $\mathrm{Y}$ represent gross scores, and $\mathrm{x}$ and $\mathrm{y}$ represent deviations from the mean.

$r$ is the usual Pearson correlation coefficient. It eamals unity if $\mathrm{Y}=\mathrm{aX}+\mathrm{b}$ or if $\mathrm{y}=\mathrm{ax}$, it equals zero if $\Sigma \mathrm{xy}=0$, and it equals -1.0 if $y=-a x$.

$R_{1}$ depends only on deviation scores. It is unity if $X_{i}-\bar{X}=Y_{i}-\bar{Y}$ or $x_{i}=y_{i}$ for all $i$, and equals zero if $\Sigma x y=0$, and equals -1.0 if $x_{i}=-y_{i}$ for all $i$.

$R_{2}$ is an index which equals 1.0 if $X_{i}=Y_{i}$ for all $i$; and equals zero if $\Sigma(\mathrm{X}+\mathrm{v})^{2}$ equals $\Sigma(\mathrm{X}-\mathrm{Y})^{2}$; and equals -1.0 if $X_{i}=-Y_{i}$ for all $i$.

Values of $r, R_{1}$, and $R_{2}$ for $R_{h o}$ and alpha are shown in Table 5. For the other parameters, so few of the values were nonzero that values of $r, R_{1}$, and $R_{2}$ could not be computed.

Since it is theorized that learning measures in the split-brain animals would be equal for left and right paw performance on the same tactile problem, the values of $\mathbf{R}_{\mathbf{2}}$ should be large if the measures were equal. These values are uniformly low from .13 to -.15 . Where $R_{2}$ is small, even though $r$ is large, it indicates that though the correlation may be high, the values of $\mathrm{X}$ and $\mathrm{Y}$ are far from equal. $\mathbf{R}_{\mathbf{1}}$ expresses the relationships between deviations from the mean.

In general, these results from analyzing the data in terms of learning-curve parameters did not agree with previous reports that second-paw learning in split-brain animals is a replication of first-paw learning of tactile problems. For these previous reports see Sperry (1961), Stamm and Sperry (1957), Meikle, Sechzer, and Stellar (1962) and Glickstein and Sperry (1960). As a quantitative measure of similarity of learning, these reports used the conventional measures of total trials, errors or correct responses to criterion, so it seemed reasonable to consider the possibility that the conventional measures might show replication when learning-curve parameters did not. Therefore, the data were also analyzed in terms of these conventional measures.

The savings score on total trials is given as a percentage:

$$
\frac{\text { trials on No. } 1 \text { paw }- \text { trials on No. } 2 \text { paw }}{\text { trials on No. } 1 \text { paw }} \times 100
$$

The normal WR animals showed savings scores on total trials ranging from $+33 \%$ to $+55 \%$ on problem ba. The split-brain animals with the corpus callosum sectioned showed equally large positive savings scores, which was not expected with the view that the two halves of the brain were acting somewhat independently and in a like manner. On the $\mathrm{dc}$ and hg problems, the normal animals showed savings scores both positive and negative. For the split-brain animals, savings scores ranged from $+85 \%$ to $-74 \%$, the great majority being positive scores.

Total trials to criterion for riormal and operated animals for the PR group were calculated. On problems $\mathrm{dc}$ and $\mathrm{cd}$, the normal animals, and those with cc-ac after the first-paw learning, showed savings scores of $83 \%$ to $96 \%$ positive, indicating a high degree of transfer on these problems as expected with normal animals. There was also a high degree of transfer on the fe, ef problems except for one case. On subsequent problems with the animals operated for $\mathrm{cc}-\mathrm{ac}$, the problems hg, gh, df, fd, and $a b$ were too difficult for most of the animals. On the ba problems (11-14), where a high degree of learning took place, savings scores on total trials were negative $-2 \%$ to $-20 \%$ for the operated animals.

Figures 3 and 4 summarize the data on total trials for split-brain cats. These show that for the WR group, the second-paw learning is accomplished with fewer trials than the first-paw learning (on Problems 1-6) regardless of whether the left or right paw was first. For the PR group, first- and second-paw learning trials (on Problems 11-14) were approximately equal. The second-paw learning usually required a few more trials than the first-paw learning, regardless of whether the left or right paw learned first.

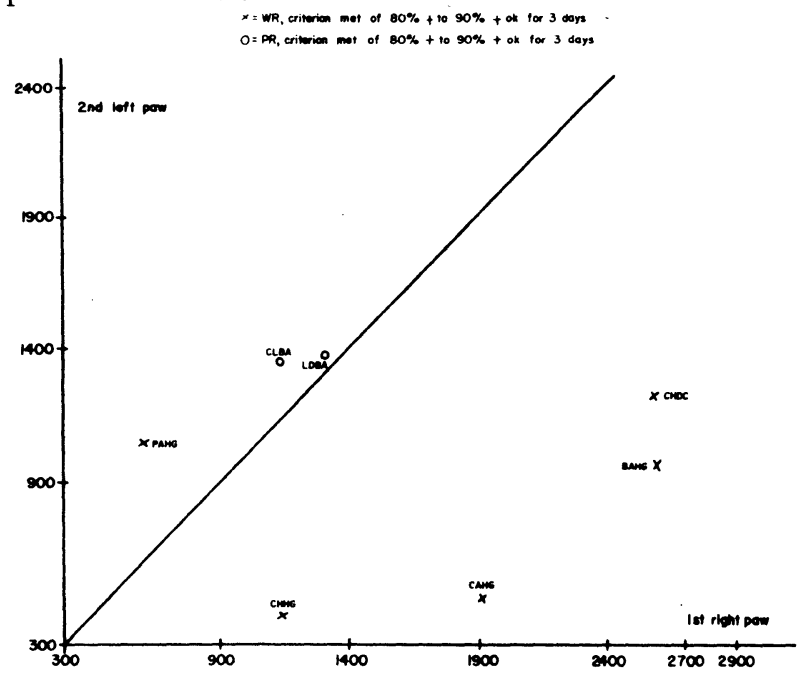

Figure 3. Total trials, split-brain cats, right paw first. 
Table 6

Total Number of Errors to Three Highest Days for the WR Group

\begin{tabular}{|c|c|c|c|c|c|c|c|}
\hline Code & $\begin{array}{l}\text { First } \\
\text { Paw }\end{array}$ & $\begin{array}{c}\text { Percent } \\
\text { OK in } \\
3 \mathrm{SD}\end{array}$ & $\begin{array}{c}\text { Second } \\
\text { Paw }\end{array}$ & $\begin{array}{c}\text { Percent } \\
\text { OK in } \\
3 \mathrm{SD}\end{array}$ & $\begin{array}{c}\text { Savings } \\
\text { Percentage } \\
\text { of No. } 1 \\
\end{array}$ & $\begin{array}{l}\quad{ }^{N} \\
\text { First } \\
\text { Paw } \\
\end{array}$ & $\begin{array}{l}\text { Op } \\
\text { Second } \\
\text { Paw }\end{array}$ \\
\hline Syba3,1-1,2 & 255 & 90 & 141 & 90 & +45 & $\mathrm{~N}$ & $\mathrm{~N}$ \\
\hline Amba 1,3-1,2 & 1218 & 90 & 375 & 90 & +69 & $\mathrm{~N}$ & $\mathrm{~N}$ \\
\hline Paba3,1-1,2 & 97 & 96 & 27 & 99 & +72 & $\mathrm{~N}$ & $\mathrm{~N}$ \\
\hline Chba3,1-1,2 & 180 & 95 & 209 & 96 & -16 & $\mathrm{~N}$ & Opt \\
\hline Arba 1,3-1,2 & 293 & 90 & 365 & 90 & -25 & Op & Op \\
\hline Toba1,3-1,2 & 581 & 90 & 102 & 90 & +82 & Op & Op \\
\hline Caba3,1-1,2 & 652 & 90 & 167 & 90 & +74 & Op & Op \\
\hline Hoba 1,3-1,2 & 331 & 90 & 253 & 90 & +24 & Op & $\mathrm{Op}$ \\
\hline Sydc2,4-3,4 & 979 & 90 & 435 & 98 & +55 & $\mathrm{~N}$ & $\mathrm{~N}$ \\
\hline Amdc $2,4-3,4$ & 255 & 92 & 374 & 96 & -47 & $\mathrm{~N}$ & $\mathrm{~N}$ \\
\hline Padc2,4-3,4 & 214 & 90 & 134 & 90 & +37 & Op & Op \\
\hline Badc $3,1-3,4$ & $*$ & & $*$ & & & Op & Op \\
\hline Chdc $4,2-3,4$ & 907 & 95 & 371 & 98 & +59 & $\mathrm{Op}$ & Op \\
\hline Ardc2,4-3,4 & 229 & 95 & 109 & 96 & +52 & Op & Op \\
\hline Todc $2,4-3,4$ & $*$ & & $*$ & & & Op & Op \\
\hline Cadc $2,4-3,4$ & 463 & 91 & 407 & 95 & +12 & Op & $\mathrm{Op}$ \\
\hline Hocd 1,3-3,4 & 682 & 92 & 219 & 92 & +68 & Op & Op \\
\hline Amhg $1,3-5,6$ & 441 & 95 & 10 & 97 & +98 & $\mathrm{~N}$ & $\mathrm{~N}$ \\
\hline Pahg3,1-5,6 & 164 & 90 & 384 & 92 & -134 & Op & Op \\
\hline Bahg3,1-5,6 & 598 & 95 & 234 & 97 & +61 & Op & Op \\
\hline Chhg3,1-5,6 & 338 & 90 & 79 & 97 & +77 & Op & Op \\
\hline Arhg1,3-5,6 & 13 & 90 & 235 & 94 & -1707 & Op & $\mathrm{Op}$ \\
\hline Tohg1,3-5,6 & 640 & 93 & 476 & 94 & +26 & Op & Op \\
\hline Cahg $3,1-5,6$ & 679 & 93 & 94 & 99 & +86 & $\mathrm{Op}$ & Op \\
\hline Hohg1,3-5,6 & 713 & 95 & 124 & 92 & +80 & $\mathrm{Op}$ & Op \\
\hline
\end{tabular}

Note-Code: First two letters = cat; second two letters = problem. First two digits = sequence of paw used; $1,2=$ left; 3,4 $=$ right. Second set of digits = sequence number of problem.

*Criterion of learning not reached.

fOp: Cats Ch, To, and Ca had the corpus callosum sectioned; Cats Pa, Ar, Ho, and Ba had the anterior commissure also sectioned.

Table 7

Total Number of Errors to Three Highest Days for the PR Group

\begin{tabular}{|c|c|c|c|c|c|c|c|}
\hline Code & $\begin{array}{l}\text { First } \\
\text { Paw }\end{array}$ & $\begin{array}{l}\text { Percent } \\
\text { OK in } \\
3 \mathrm{SD}\end{array}$ & $\begin{array}{c}\text { Second } \\
\text { Paw }\end{array}$ & $\begin{array}{l}\text { Percent } \\
\mathrm{OK} \text { in } \\
3 \mathrm{SD}\end{array}$ & $\begin{array}{l}\text { Savings } \\
\text { Percentage } \\
\text { of No. } 1 \\
\end{array}$ & $\begin{array}{l}\text { First } \\
\text { Paw } \\
\end{array}$ & $\begin{array}{l}\text { Second } \\
\text { Paw }\end{array}$ \\
\hline $\begin{array}{l}\text { Rudc3,1-2,6 } \\
\text { Fidc1,3-2,6 } \\
\text { Evcd2,4-2,6 } \\
\text { Ldcd4 } 2-2,6 \\
\text { Clcd4,2-2,6 }\end{array}$ & $\begin{array}{r}116 \\
183 \\
1280 \\
433 \\
466\end{array}$ & $\begin{array}{l}90 \\
90 \\
90 \\
88 \\
85\end{array}$ & $\begin{array}{r}8 \\
7 \\
74 \\
51 \\
47\end{array}$ & $\begin{array}{l}94 \\
83 \\
90 \\
89 \\
90\end{array}$ & $\begin{array}{l}+93 \\
+96 \\
+94 \\
+88 \\
+90\end{array}$ & $\begin{array}{l}\mathrm{N} \\
\mathrm{N} \\
\mathrm{N} \\
\mathrm{N} \\
\mathrm{N}\end{array}$ & $\begin{array}{l}\mathrm{N} \\
\mathrm{Op} \\
\mathrm{N} \\
\mathrm{Op} \\
\mathrm{N}\end{array}$ \\
\hline $\begin{array}{l}\text { Fife 1,3-4,5 } \\
\text { Evef } 2,4-4,5 \\
\text { Ldef } 4,2-4,5 \\
\text { Clef } 4,2-4,5\end{array}$ & $\begin{array}{r}26 \\
54 \\
1 \\
34\end{array}$ & $\begin{array}{l}100 \\
100 \\
100 \\
100\end{array}$ & $\begin{array}{r}11 \\
0 \\
0 \\
34\end{array}$ & $\begin{array}{r}100 \\
100 \\
96 \\
95\end{array}$ & $\begin{array}{r}+58 \\
+100 \\
+100 \\
0\end{array}$ & $\begin{array}{l}\mathrm{N} \\
\mathrm{N} \\
\mathrm{N} \\
\mathrm{N}\end{array}$ & $\begin{array}{l}\mathrm{N} \\
\mathrm{N} \\
\mathrm{N} \\
\mathrm{N}\end{array}$ \\
\hline $\begin{array}{l}\text { Ruab3,1-13,14 } \\
\text { Fiab1,3-13,14 } \\
\text { Evab1,3-11,12 } \\
\text { Ldab3,1-11,12 } \\
\text { Clab3,1-11,12 }\end{array}$ & $\begin{array}{l}602 \\
702 \\
966 \\
630 \\
573\end{array}$ & $\begin{array}{l}79^{*} \\
78^{*} \\
66^{*} \\
68^{*} \\
71^{*}\end{array}$ & $\begin{array}{r}96 \\
586 \\
514 \\
887 \\
732\end{array}$ & $\begin{array}{l}75^{*} \\
75^{*} \\
56^{*} \\
57^{*} \\
71^{*}\end{array}$ & $\begin{array}{l}+84 \\
+17 \\
+47 \\
-41 \\
-28\end{array}$ & $\begin{array}{l}N \\
O p \\
O p \\
O p \\
O p\end{array}$ & $\begin{array}{l}N \\
O p \\
O p \\
O p \\
O p\end{array}$ \\
\hline $\begin{array}{l}\text { Ruba4,2-11,12 } \\
\text { Fiba2,4-11,12 } \\
\text { Evba2,4-13,14 } \\
\text { Ldba4,2-13,14 } \\
\text { Clba4,2-13,14 }\end{array}$ & $\begin{array}{l}352 \\
360 \\
522 \\
478 \\
338\end{array}$ & $\begin{array}{l}92 \\
94 \\
86 \\
87 \\
90\end{array}$ & $\begin{array}{l}551 \\
284 \\
672 \\
530 \\
350\end{array}$ & $\begin{array}{l}77^{*} \\
96 \\
97 \\
81 \\
93\end{array}$ & $\begin{array}{r}-57 \\
+21 \\
-29 \\
-11 \\
-4\end{array}$ & $\begin{array}{l}N \\
O p \\
O p \\
O p \\
O p\end{array}$ & $\begin{array}{l}N \\
O p \\
O p \\
O p \\
O p\end{array}$ \\
\hline
\end{tabular}

Note-Code: First two letters = cat; second two letters = problem. First two digits = sequence of paw used; $1,2=$ left; $3,4=$ right . Second set of digits = sequence of problem.

${ }^{*}$ Criterion of learning not reached. 


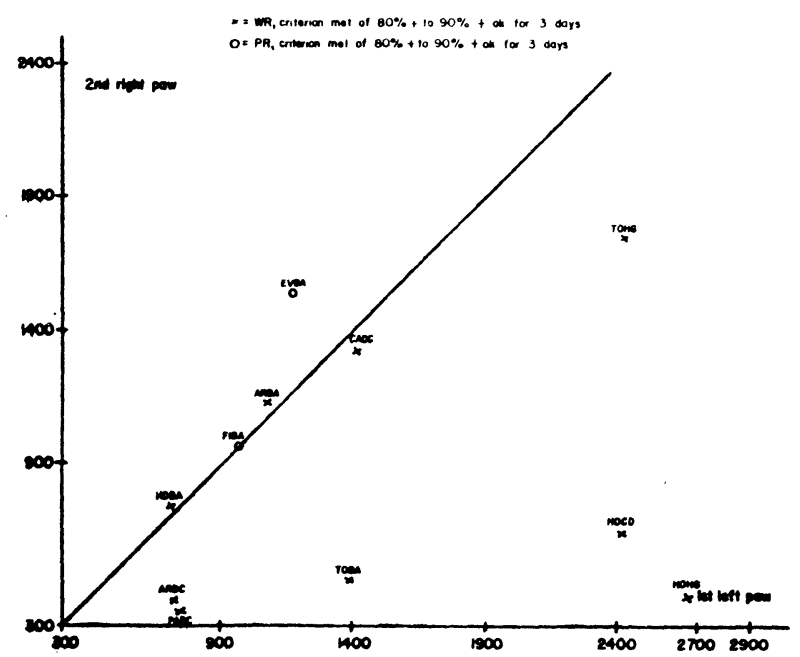

Figure 4. Total trials, split-brain cats, left paw first.

Total errors to criterion for the normal and cc-ac operated cats and savings scores for the WR group are shown in Table $\overline{6}$. Large positive and negative scores were found for both normal and operated animals. The positive scores predominated. Total errors to criterion for the normal and operated cats and savings scores for the PR group are shown in Table 7. Large positive scores for normals on $\mathrm{dc}, \mathrm{cd}, \mathrm{fe}$, and ef problems occurred. These problems were all learned to criterion. Such positive transfer was expected for the normal animals and those who did the first problem in the normal state and then had the cc-ac operation before doing the second-paw problem. For the ba problem, there was less deviation from zero for the operated PR cats than for the operated WR cats on the same problem. It may be noted that the ba problem was the first one given to the WR group, while it was the sixth or seventh pair for the PR group, who were then more experienced in the apparatus.

The comparison of total errors to criterion for first vs second paw for operated animals that reached criterion is shown in Figure 5. Learning occurred in the case of problem ba for the PR group, and the pairs of error values fall close to the $X=Y$ line for this group.

Table 8 gives a summary of $r, R_{1}$, and $R_{2}$ values as described in connection with Table 5, for total trials, total correct, and total errors to criterion for operated

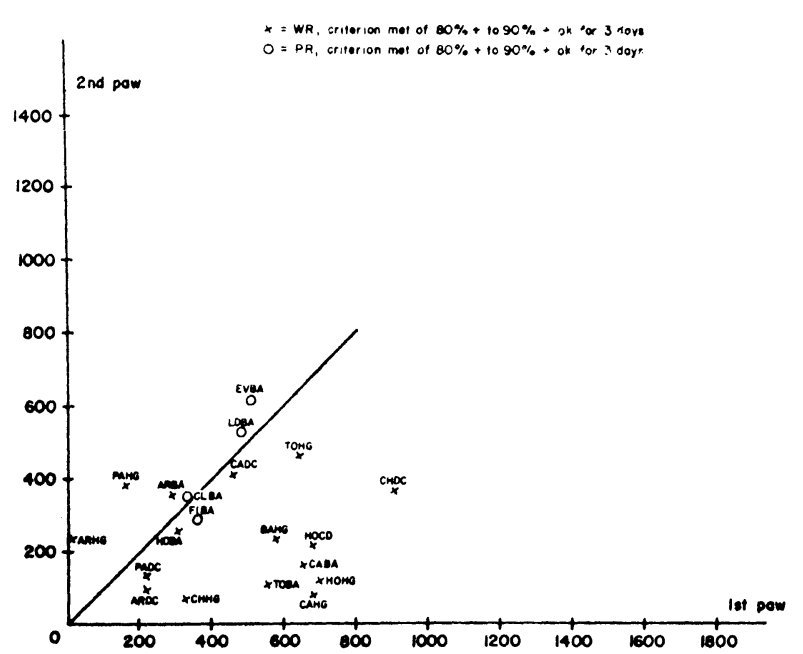

Figure 5. Number of errors to criterion, split-brain cat.

animals that learned the problems. For the ba problem, there is a high correlation for the PR group of four cases. An equally high negative correlation appears for three ba cases in the WR group. The $\mathbf{R}_{\mathbf{2}}$ values are similar to the correlations in this instance.

\section{DISCUSSION}

In general, then, we find the same result for the conventional measures as for the learning parameters. The second-paw results cannot generally be regarded as replications of first-paw results. Great variability in response was encountered within and between animals. In terms of conventional measures, the results on normal animals agreed with the results of other investigators. These animals showed, in general, marked savings on second-paw learning in problems where the criterion was reached, indicating a high degree of transfer as expected.

In the results with split-brain animals, great variability in response was encountered within and between animals. It is of interest to note the finding that the values of $r, R_{1}$ and $R_{2}$ are exceptionally high for the four split-brain PR cats, considering total trials, total errors, and total correct responses to criterion. The ba problem used in this case, with brush positive, flat wood block negative, was one of moderate difficulty that all of the animals could learn. Since it was the 11 th to 14th

Table 8

Relationships Between Left- and Right-Paw Learning Measures in Split Brain Cats: Total Trials, Number Correct, and Number of Errors to Criterion

\begin{tabular}{lrrrc}
\hline Measure & \multicolumn{1}{c}{$\mathbf{R}_{2}$} & $\mathbf{R}_{1}$ & $\mathrm{r}$ & Number of Cases \\
\hline Total Trials & 0.352 & 0.680 & 0.771 & 4 Pairs PR (all ba) \\
Total Trials & -0.204 & 0.122 & 0.166 & 14 Pairs WR \\
Number of OK Trials & 0.171 & 0.671 & 0.679 & 4 Pairs PR (all ba) \\
Number of OK Trials & -0.059 & 0.272 & 0.334 & 14 Pairs WR \\
Number of Errors & 0.737 & 0.770 & 0.956 & 4 Pairs PR (all ba) \\
Number of Errors & -0.276 & 0.063 & 0.071 & 14 Pairs WR \\
Number of Errors & -0.957 & -0.937 & -0.950 & 3 Pairs WR (all ba) \\
\hline
\end{tabular}


problem in the animals' series, the animals were thoroughly accustomed to the experimental situation with disturbing influences at a minimum. The disturbing elements influencing certain cats were apparent in the early experiments, when the animals were normal. Some animals refused to work if not successful in obtaining food rewards, and the experimental box would be avoided in some cases with snarling and meowing. This situation was remedied by giving liver pellets instead of dry food in the automatic food drop. These observations are offered as related to our finding that the most stable results, and those agreeing to some extent with the view of equal learning through the separate hemispheres of the cat, were found using a problem all cats could learn, giving a desired food reward, and suppressing repeated incorrect responses.

Russell, Plotkin, and Kleinman (1970) studied learning in the functional split-brain rat and report that split-brain animals showed marked emotional responses. "Classically conditioned CERs (conditioned emotion responses) failed to lateralize, but they did not facilitate the acquisition of escape behavior with the new hemisphere." When these investigators compared the mean number of trials required to reach each of five different criteria of learning (CL) an almost perfect correlation was found. This held, however, only for the means of groups trained to different criteria. On comparing individual results, the correlations were near zero. These findings do not agree with the view that second-brain learning replicates first-brain learning.

Variability of response was discussed by Voneida and Robinson (1970) and Robinson and Voneida (1973) in their investigations of performance on visual problems under monocular vs binocular input in normal and split-brain cats. Glickstein and Sperry (1960), working with rhesus monkeys, noted that position habits did develop and "nonspecific effects" confounded the savings scores. These investigators used as a comparison measure the first 40 trials of the second paw on a tactile problem. This is similar to the $\mathrm{Rho}_{0}$ measure in the present study (initial probability of a correct response). Myers (1956), using cats, discusses deterrent effects of position habits on learning visual problems and on measuring unrewarded transfer tests. The most stable results in the present study were found using problems all cats could learn, giving a desired reward, and suppressing repeated incorrect responses.

Meikle, Sechzer, and Stellar (1962) studied respiratory and flexion responses to shock paired with skin stimulation. Respiratory responses were rapidly relearned, but limb flexion failed to demonstrate any transfer in the corpus callosum sectioned cats and required complete retraining. They suggest that the degree of hemispheric interaction depends largely upon the type of response learned, with highly corticalized responses (such as limb flexion) appearing to require an intact corpus callosum during training.
Some results reported by Best (1965) in his thesis are of interest. He reported results from a reanalysis of data supplied by Meikle $(1960,1964)$ and by Meikle and Sechzer (1960) on visual problems. There were nine animals with transection of the corpus callosum and optic chiasma, four of whom had deep split-brain sections. A brightness problem and a figure problem were studied. A high correlation was found between first- and second-eye learning with savings scores ranging from $-10 \%$ to $+20 \%$. He fitted curves to the data and got values of alpha and gamma 2 - beta (which Best termed $S$ ) with high correlations.

Finally, the recent studies of Robinson and Voneida (1970) and of Webster (1972) have demonstrated that a considerable degree of functional asymmetry exists between the two brain halves. Results obtained in the present study are in general agreement with the latter, in that they fail to support the idea that the two hemispheres are identical. It must be concluded, therefore, that under conditions of the present experiment at least, the two brain halves, surgically separated by forebrain commissurotomy, may function as quite dissimilar units.

Possibly under some conditions, second-brain learning replicates first-brain learning, and under other conditions there is no such replication. If limited conditions under which second-brain learning replicates first-brain learning do exist, then an investigation of learning-curve theories through replication by split-brain experiments would be possible.

\section{REFERENCES}

Atkinson, R. C. Studies in mathematical psychology. Stanford, California: Stanford University Press, 1964, Pp. viii, 414. Audley, R. J., \& Jonckheere, A. R. The statistical analysis of the learning process. II. Stochastic processes and learning behavior. British Journal of Statistical Psychology, 1956, 9, 87-94.

Best, $\mathbf{P}$. J. An experimental investigation of a mathematical learning model. Unpublished doctoral dissertation, Princeton University, 1965. (Also Office of Naval Research Technical Report and ETS Research Bulletin 66-15. Educational Testing Service, Princeton, N. J., 1966.)

Glickstein, M., \& Sperry, R. W. Intermanual somesthetic transfer in "split-brain" rhesus monkeys. Journal of Comparative and Physiological Psychology, 1960, 53, 322-327.

Gulliksen, $H$. A rational equation of the learning curve based on Thorndike's Law of Effect. Journal of General Psychology, 1934, 11, 395-434.

Gulliksen, H. A generalization of Thurstone's learning function. Psychometrika, 1953, 18, 297-307.

Meikle, T. H., Jr. Role of the corpus callosum in transfer of visual discriminations in the cat. Science, 1960, 132, 1496.

Meikle, T. H., Jr. Failure of interocular transfer of brightness discrimination. Nature, 1964, 202, 1243-1244.

Meikle, T. H., Jr., \& Sechzer, J. A. Interocular transfer of brightness discrimination in "split brain" cats. Science, 1960, $132,734-735$.

Meikle, T. H., Jr., Sechzer, J. A., \& Stellar, E. Interhemispheric transfer of tactile conditioned responses in corpus callosum-sectioned cats. Journal of Neurophysiology, 1962, 25, 530-543.

Myers, R. E. Function of the corpus callosum in interocular transfer. Brain, 1956, 79, 358-363.

Ramsay, J. O. A family of gradient methods for optimization. Computer Journal, 1970, 13, 413-417.

Robinson, J. S., \& Voneida, T. J. Quantitative differences in performance on abstract discriminations using one or both hemispheres. Experimental Neurology, 1970, 26, 72-83. 
Robinson, J. S., \& Voneida, T. J. Hemisphere differences in cognitive capacity in the split-brain cat. Experimental Neurology, 1973, 38, 123-134.

Russell, I. S., Plotkin, H. C., \& Kleinman, D. Task dif ficulty and lateralization of learning in the functional split-brain rat. Physiology and Behavior, 1970, 5, 469-478.

Sperry, R. W. Cerebral organization and behavior. Science, 1961 , $133,1749-1757$.

Stamm, J. S., \& Sperry, R. W. Function of corpus callosum in contralateral transfer of somesthetic discriminations in cats. Journal of Comparative and Physiological Psychology, 1957, $50,138-143$.
Voneida, T. J. Performance of a visual conditioned response in split-brain cats. Experimental Neurology, 1963, 8, 493-504.

Voneida, $T_{2} J_{3}$, \& Robinson, $J$. S. Effect of brain bisection on capacity for cross comparison of patterned visual input. Experimental Neurology, 1970, 26, 60-71.

Webster, W. G. Functional asymmetry between the cerebral hemispheres of the cat. Neuropsychologia, 1972, 10, 75-87.

(Received ror publication April 4, 1974; revision received August 28, 1974.) 